\title{
Food health potential is primarily due to its matrix structure, then nutrient composition: a new paradigm for food classification according to technological processes applied
}

\section{Editorial}

Scientific evidence clearly shows that food health potential depends on both its matrix structure (i.e., qualitative food characteristics) and nutrient composition (i.e., quantitative food characteristics). But food structure comes first because, at identical chemical composition, health potential may completely differ depending on food structure. ${ }^{1}$ Indeed, this is the food structure parameters e.g., matrix density, particle size, nutrient interactions, starch structure, etc. that will determine nutrient bioavailability, then health effects.

Except water, all natural foods provides a complex matrix including numerous energetic and non-energetic nutrients such as polyphenols, carotenoids, vitamins, minerals and trace elements. This is why technological processes are so important; because they affect both food structure and chemical composition, for the best or for the worst. ${ }^{2,3}$ Raw natural foods are quite neutral in nature, differing in food structure and chemical composition depending on botanical origin, genetic breeding, animal species and agricultural conditions. Therefore, they have all a potential health benefit. It is rare that a food is not submitted to processing; even simple storing being a process that can modify food health potential e.g., vitamins losses It is therefore not exaggerated to conclude that all comes down to human intervention i.e., food processing for determining final food health potential.

Today, it is therefore more relevant to classify foods according to the intensity of the technological processes applied i.e., natural/ minimally-processed, culinary ingredients, processed, and ultraprocessed foods ${ }^{4}$ and not according to their botanical or animal species origins, as mostly realized up today notably in human epidemiological studies. ${ }^{5}$ This will lead to avoid demonizing or putting to the firmament some foods or food groups whereas the real issue is not here. The real issue is both the nature of technological processes applied and our way of eating. Very recently, new Brazilian dietary guidelines have been released: they are the first to give nutritional recommandation based on food processing classification. We can hope that other countries will follow this classification because it is the most relevant for health outcomes of populations world wide. ${ }^{6}$ And, as more and more new studies are published each year, this will avoiding endless scientific discussions or debates about the pros and the cons toward health for a given food group for nutritional recommandations. This will also avoiding often contradictory results obtained for a given food group toward chronic disease prevalences when synthesizing them in systematic reviews or meta-analyses. ${ }^{5}$ Why such contradictory results? I think this is because food classification in epidemiological studies, as extracted from food-frequency questionnaires, is not based on the good paradigms. New paradigms for future studies should be obviously based on dietary patterns, but also on consumed foods
Volume I Issue 5 - 2014

\author{
Anthony Fardet \\ Department of Human Nutrition, National Institute of \\ Agronomic Research (INRA), France
}

Correspondence: Anthony Fardet, Department of Human Nutrition, National Institute of Agronomic Research (INRA), BP 10448, F-63000 CLERMONT-FERRAND \& Clermont University, University of Auvergne, UMR I019, UNH, CRNH Auvergne, France, Tel +33(0)473624704,

Email anthony.fardet@clermont.inra.fr

Received: November 27, 2014 | Published: November 27, 2014

depending on technological processes-based classification.

Therefore, all comes down to processing. And research food scientists and nutritionists should largely much more work together to develop technological processes more respectful of food, both for their matrix structure and chemical composition. The most damaging food processes are today refining, fractionation-recombination followed by salt, fat and simple sugar supplementation, and extrusioncooking at very high temperatures and pressures. They have led to the marketing of numerous ultra-processed foods, snacks, ready-toeat meals, sweetend beverages, etc. This is not to say that we should definitively avoid consuming these foods, but rather that natural/ minimally-processed foods should become the basis of our diets while respecting cultural habits.

Finally, with increasing urbanization of worldwide populations, which choices should we made? Do we want to direct toward more and more ultra-processed, palatable and poorly satiating foods ? Or towards more traditional, nutrient-dense and satiating foods? This will also lead to carry out a deep reflexion about the sustainability of such a new nutritional transition from industrial to more traditional and minimally-processed foods. It is a complex equation because fruits and vegetables are environmentally costly (e.g., green house gas production) while highly refined and energy-dense foods are not so much environmentally costly. ${ }^{7}$ Therefore, it is time to collecte available data worldwide (big data) to be able to modelize dietary patterns, then food systems, that are sustainable for health, environment, socio-economics, and cultural habits. It is highly probable that such modelized food systems will differ from one country to another, and from rural to urban populations as well. 


\section{Acknowledgements}

None.

\section{Conflict of interest}

Author declares that there is no conflict of interest.

\section{References}

1. Fardet A. A shift toward a new holistic paradigm will help to preserve and better process grain product food structure for improving their health effects. Food Funct. 2015;6(2):363-382.

2. Fardet A. Are technological processes the best friends of food health potential? Adv Nutr Food Technol. 2014;1(1):103.
3. Fardet A. Foods and health potential: is food engineering the key issue? J Nutr Health Food Engineer. 2014;1(4):1-2.

4. Monteiro CA, Moubarac JC, Cannon G, et al. Ultra-processed products are becoming dominant in the global food system. Obesity Reviews. 2013;14(Suppl 2):21-28.

5. Fardet A, Boirie Y. Associations between food and beverage groups and major diet-related chronic diseases: an exhaustive review of pooled/ meta-analyses and systematic reviews. Nutr Rev. 2014;72(12):741-762 .

6. Monteiro CA, Levy RB, Claro RM, et al. Increasing consumption of ultra-processed foods and likely impact on human health: evidence from Brazil. Public Health Nutr. 2011;14(1):5-13.

7. Tilman D, Clark M. Global diets link environmental sustainability and human health. Nature. 2014;515(7528):518-522. 